\title{
Spinal Cord Stimulation: Modeling Results and Clinical Data
}

\author{
Johannes J. Struijk "), Jan Holsheimer "), Giancarlo Barolat ${ }^{2)}$, Jiping He ${ }^{2)}$ \\ 1) Biomedical Eng. Div., Dept. Electr. Eng., Univ. of Twente, The Netherlands. \\ 2) Dept. Neurosurgery, Jefferson Medical College, Philadelphia, PA, USA.
}

\begin{abstract}
The potential distribution in volume conductor models of the spinal cord at cervical, midthoracic and lowthoracic levels, due to epidural stimulation, was. calculated. Treshold stimuli of modeled myelinated dorsal column and dorsal root fibers were calculated and were compared with perception thresholds obtained from measurements in patients at corresponding spinal levels.
\end{abstract}

\section{INTRODUCTION}

In order to understand the immediate effects (activation of spinal cord nerve fibers) in epidural Spinal Cord Stimulation the potential field applied by electrical stimulation and the response of neural elements in the spinal cord to the imposed field, should be known. We used a volume conductor model of the spinal cord and its surroundings at three vertebral levels to calculate the potential field due to stimulation. The calculated field was then applied to models of myelinated dorsal column (DC) fibers and dorsal root (DR) fibers to calculate threshold stimuli of those fibers.

In the present initial validation study the influence of the width of the dorsal csf-layer, the contact separation in bipolar stimulation and the laterality of the electrodes, on the threshold stimuli were investigated. The calculated threshold stimuli were compared with perception thresholds measured in patients.

\section{METHODS}

\section{A. Volume Conductor Models}

3D-conductor models of the spinal cord at midcervical, midthoracic and lowthoracic vertebral levels were used to calculate the potential field in the spinal cord. A transverse section of a midthoracic model is shown in fig. 1 together with the gridlines $(56 \times 56 \times 56$ volume elements). The models consist of gray matter (gm) white matter (wm) cerebrospinal fluid (csf), epidural space (es), vertebral bone (vb), electrode (el), isolation (is) and a surrounding layer (sl). The electrodes were voltage sources with contact dimensions $3.6 \times 3.6 \mathrm{~mm}$, thus matching the contact areas of the Medtronic Resume lead. Bipolar configurations with a center separation of $10 \mathrm{~mm}, 20 \mathrm{~mm}$ and $30 \mathrm{~mm}$ as well as a unipolar configuration were used. For each model three values of the width of the dorsal cerebrospinal fluid were used: the median, $25^{\text {th }}$ - and $75^{\text {th }}$-percentile of a population of measured csf-widths (MRI- and CT-scan data).
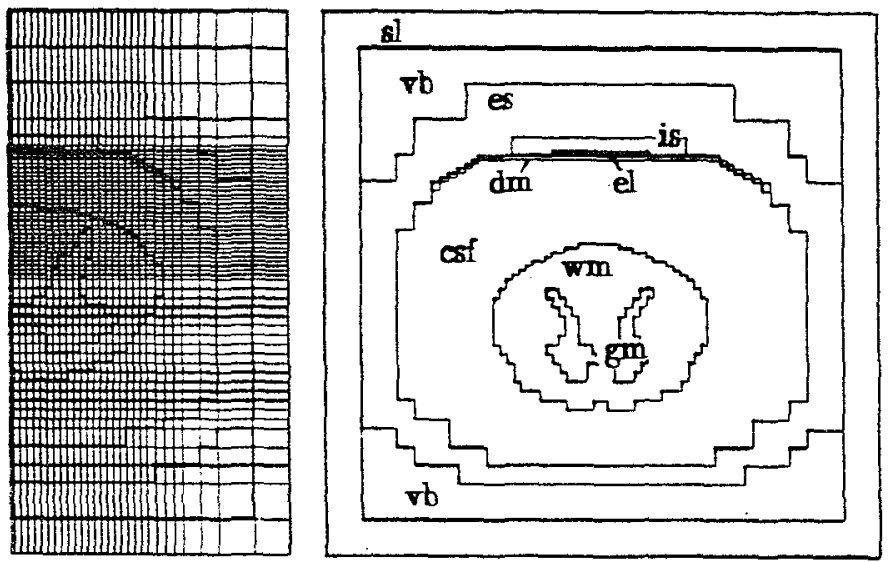

Fig. 1. Transverse section of a midthoracic spinal cord model (right); gridlines in a section of a cervical spinal cord model (left).

\section{B. Nerve Fiber Models}

Two types of myelinated nerve fiber models were used: models of DC-fibers and of DR-fibers. DC-fibers are longitudinal fibers in the dorsal columns issuing collaterals into the gray matter. The model is a McNeal like cable model [1] with membrane kinetics as described by Chiu et al. [2], extended with collaterals [3] (see fig. 2).

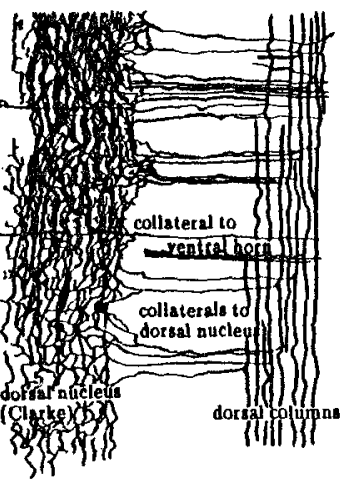

a

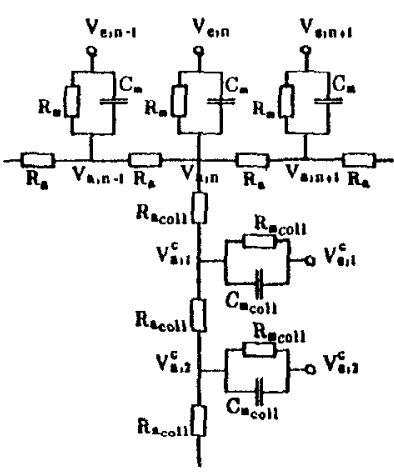

b
Fig. 2. Dorsal column fibers. a) Rostrocaudal DC-fibers with collaterals (from Cajal), b) Network model of a DC-fiber consisting of a rostrocaudal fiber (horizontal part) and a collateral (vertical).

For the DR-fiber we used a cable model with a curved trajectory (see fig. 3), the proximal end being connected to a DC-fiber model.

The fiber models were given diameters which are in the 

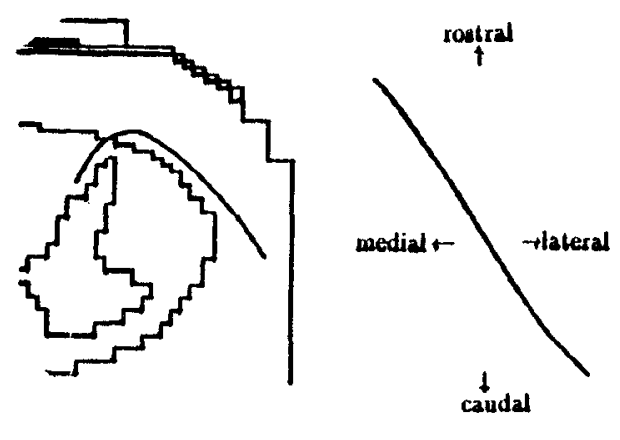

a transverse

b coronal

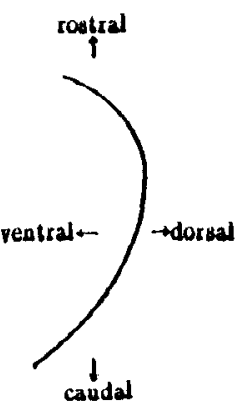

Fig. 3. Projections of the DR-fiber on three orthogonal planes. a) DR-fiber in a transverse plane, b) coronal plane, c) sagittal plane.

upper range of the diameter distribution of those fibers. DR-fiber diameter was $15 \mu \mathrm{m}$ [4], DC-fiber close to dorsal root entry zone: $12 \mu \mathrm{m}$ [5], DC-fiber dorsomedial:7.5 $\mu \mathrm{m}$ [6]. The stimulus pulse width was $210 \mu \mathrm{s}$.

\section{Clinical Data}

Perception threshold was measured in patients with an implanted pulse generator (repetition rate $50 \mathrm{pps}$, pulse width $210 \mu \mathrm{s})$. Data were obtained from patients having the electrodes at vertebral levels C4-C6 (31 patients), T4-T7 (24) and T10-T11 (53). From these perception thresholds the median, the $25^{\text {th }}$ - and $75^{\text {th }}$-percentiles with their $95 \%$ confidence intervals were calculated.

\section{RESULTS}

\section{A. Perception Threshold as a Function of Spinal Level}

We calculated the threshold stimulus $V_{\text {calc }}$ of DC-fibers and DR-fibers at the three spinal levels with an electrode separation of $10 \mathrm{~mm}$ and a dorsal csf-width being the median of the measured values, at each level. DC-fiber thresholds were higher than DR-fiber threshold. In both the model and the clinical data thresholds were lowest at cervical level, due to the small dorsal csf-layer at that level. Calculated thresholds were about a factor 2 too high compared to clinical data, presumably because average values of fiber parameters were used.

\section{B. Perception Threshold as a Function of csf-width}

We calculated $V_{\text {calc }}$ in the models at the three spinal levels with dorsal csf-widths being the median, $25^{\text {th }} \%$ and $75^{\text {th }}$ - $\%$ of the measured csf-widths. These $V_{\text {calc }}$ (normalized to the values at median csf-widths) were compared to the median, $25^{\text {th }}-\%$ and $75^{\text {th }}$ \% $\%$ of the (normalized) measured values at the three levels. The calculated values were well within the $95 \%$-confidence intervals of the clinical data, at all three levels.

The $25^{\mathrm{t}}-\%$ values were about $70 \%$ of the median values whereas the $75^{\text {th }} \%$ values were circa $150 \%$.

The results support the assumption that the variation of measured perception threshold can be attributed mainly to the variation of csf-width.

\section{Perception Threshold as Function of Contact Separation}

In the three models $\mathrm{V}_{\text {calc }}$ was calculated with median dorsal csf-width and a contact separation of $10 \mathrm{~mm}, 20 \mathrm{~mm}$ and $30 \mathrm{~mm}$ as well as for some smaller and larger values. At cervical level $V_{\text {calc }}$ was $100 \%, 94 \%$ and $104 \%$ at 10 $\mathrm{mm}, 20 \mathrm{~mm}$ and $30 \mathrm{~mm}$ contact separation respectively (values normalized to $\mathrm{V}_{\text {calc }}$ at $10 \mathrm{~mm}$ separation). For smaller contact separation $V_{\text {calc }}$ sharply increased while for larger separation $\mathrm{V}_{\text {calc }}$ slowly increased.

These values were in agreement with the clinical data (95\% confidence) which was also true at midthoracic and lowthoracic levels.

\section{Influence of the Lateral Position of the Contacts}

Thresholds as well as paresthesia distributions are largely affected by the laterality of the contacts. The average perception threshold at thoracic levels, for bipolar combinations with contacts at $0-3 \mathrm{~mm}$ from midline was $1.7 \mathrm{~V}$ (100\%), for contacts at $3-5 \mathrm{~mm}$ from midline it was $70 \%$ and for contacts $>5 \mathrm{~mm}$ it was $47 \%$ [7].

In the model a lateral shift of the contacts from midline to $3 \mathrm{~mm}$ from midline decreased threshold stimulus to $80 \%$.

\section{CONCLUSION}

Except for the absolute values of the thresholds, the modeling results are in good agreement with the clinical data. More reliable data on some model parameters are needed to remove the discrepancy. The model may be used to predict the effects of various electrode configurations and may thus be a guideline in the design of new electrodes.

\section{REFERENCES}

[1] D.R. McNeal, "Analysis of a model for excitation of myelinated nerve", IEEE Trans. Biomed. Eng., vol.23, pp.329-337, 1976.

[2] S.Y. Chiu, J.M. Ritchie, R.B. Rogart, D. Stagg, "A quantitative description of membrane currents in rabbit myelinated nerve", $J$. Physiol., vol.292, pp.149-166, 1979.

[3] J.J. Struijk, J. Holsheimer, G.G. van der Heide, H.B.K. Boom, "Recruitment of dorsal column fibers in spinal cord stimulation: Influence of collateral branching", in press.

[4] R.E.W. Fyffe, "Afferent fibers", in: R.A. Davidoff (ed), Handbook of the spinal cord, vols.2\&3, New York, Dekker, 1984.

[5] J.E. Desmedt, G. Cheron, "Central somatosensory conduction in man", Electroenc. Clin. Neurophysiol., vol.50, pp.382-403, 1980.

[6] D. Petit, P.R. Burgess, "Dorsal column projection of receptors of cat hairy skin supplied by cat myelinated fibers", J. Neurophysiol., vol.31, pp.849-855, 1968.

[7] G. Barolat, S. Zeme, B. Ketcik, "Multifactorial analysis of epidural spinal cord stimulation", Stereotact. Funct. Neurosurg., vol.56, pp.77-103, 1991 . 